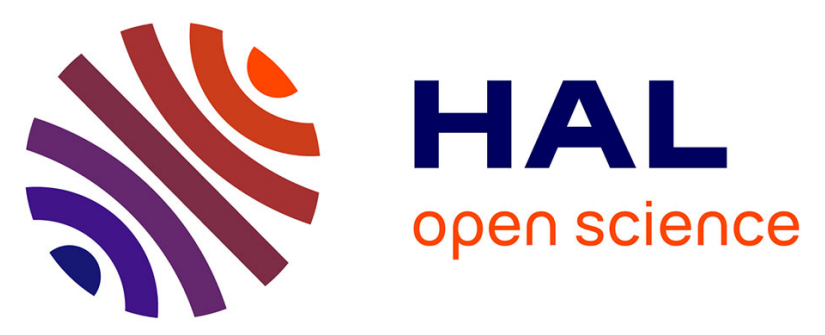

\title{
Expedient Synthesis of Thioether-Functionalized Hydrotris(indazolyl)borate as an Anchoring Platform for Rotary Molecular Machines
}

Guillaume Erbland, Yohan Gisbert, Gwénaël Rapenne, Claire Kammerer

\section{- To cite this version:}

Guillaume Erbland, Yohan Gisbert, Gwénaël Rapenne, Claire Kammerer. Expedient Synthesis of Thioether-Functionalized Hydrotris(indazolyl)borate as an Anchoring Platform for Rotary Molecular Machines. European Journal of Organic Chemistry, 2018, 2018, pp.4731 - 4739. 10.1002/ejoc.201800990 . hal-01880748

\author{
HAL Id: hal-01880748 \\ https://hal.science/hal-01880748
}

Submitted on 12 May 2020

HAL is a multi-disciplinary open access archive for the deposit and dissemination of scientific research documents, whether they are published or not. The documents may come from teaching and research institutions in France or abroad, or from public or private research centers.
L'archive ouverte pluridisciplinaire HAL, est destinée au dépôt et à la diffusion de documents scientifiques de niveau recherche, publiés ou non, émanant des établissements d'enseignement et de recherche français ou étrangers, des laboratoires publics ou privés. 


\title{
Expedient synthesis of thioether-functionalized hydrotris(indazolyl)borate as an anchoring platform for rotary molecular machines
}

\author{
Guillaume Erbland, ${ }^{[a]}$ Yohan Gisbert, ${ }^{[a]}$ Gwénaël Rapenne ${ }^{[a, b]}$ and Claire Kammerer*a]
}

[a] CEMES, Université de Toulouse, CNRS, 29, rue Jeanne Marvig, 31055 Toulouse, France E-mail: kammerer@cemes.fr

[b] Graduate School of Materials Science, Nara Institute of Science and Technology, 8916-5 Takayama, Ikoma, Nara, Japan

\begin{abstract}
Major improvements in the synthesis of surface-mounted rotary molecular machines based on ruthenium(II) complexes are reported. The development of a one-pot indium(III)-mediated " $N$ deprotection / ester reductive sulfidation" sequence allowed step economy, reproducibility and high efficiency in the synthesis of the thioether-functionalized tripodal ligand. Switching to the thallium salt of hydrotris(indazolyl)borate and to microwave heating further optimized the preparation of the common intermediate in the modular synthesis of symmetric and dissymmetric molecular motors and gears. The penta(4-bromophenyl)cyclopentadienyl ruthenium(II) key precursor is now reproducibly synthesized in 5 steps and $31 \%$ overall yield on the longest linear sequence. Subsequent five-fold Suzuki-Miyaura coupling with ferroceneboronic acid led to a new $C_{5}$-symmetric penta-ferrocenyl molecular motor.
\end{abstract}

\section{Keywords}

scorpionate ligand $\bullet$ indazole $\bullet$ reductive sulfidation $\bullet$ indium $\bullet$ molecular motor

Preprint

Submitted to Eur. J. Org. Chem. 


\section{Introduction}

The field of artificial molecular machines has witnessed a tremendous development over the last two decades, with an initial impetus related to the synthesis of mechanically interlocked systems allowing to control the motion of (at least) one of their components. ${ }^{[1,2]}$ Among nanomachines, artificial molecular motors are expected to transform the supplied energy into a unidirectional translational or rotational motion, ultimately leading to recovery of the work performed. ${ }^{[3]}$ Pioneering examples of chemicallyand light-fuelled rotary motors were reported as early as in 1999 by the groups of Kelly ${ }^{[4]}$ and Feringa, ${ }^{[5]}$ respectively, exhibiting controlled unidirectional motion in solution. Although many very elegant molecular rotary motors using chemical or light energy have been developed ever since ${ }^{[3]}$ and have shown interesting applications, ${ }^{[6]}$ the exploitation of electronic energy is still rare and only scarce examples have been reported at the single molecular scale ${ }^{[7-9]}$ or in self-assembled monolayers. ${ }^{[10]}$ Sykes and co-workers employed a butyl methyl sulfide single-molecule chemisorbed on a $\mathrm{Cu}(111)$ surface as a rotor and used the tip of a Scanning Tunneling Microscope (STM) to trigger an electrically-driven rotation. ${ }^{[7]}$ As a result, one of the enantiomeric surface-bound molecules underwent rotary motion with $5 \%$ directionality, which has been ascribed to the intrinsic chirality of the STM tip. In 2011, Feringa incorporated four overcrowded alkene-based motors acting as wheels into a molecular car scaffold and proved that the electrically-driven rotary motion of the motors can be converted into directional translation of the nanovehicle on a $\mathrm{Cu}(111)$ surface. $^{[8]}$

In this context, we reported the design and synthesis of electron-fueled molecular motor $\mathbf{1}$ displaying a dissymmetrically-substituted cyclopentadienyl rotor, a scorpionate ligand as the stator and a ruthenium(II) center as a joint allowing the rotary motion of the upper part with respect to the lower one (Figure 1). ${ }^{[1]}$ The tripodal stator was functionalized with thioether groups to ensure a strong anchorage on gold surface via chemisorption. This molecular motor was indeed studied at the single molecule scale at low temperature (5 K) under Ultra-High Vacuum (UHV) by STM. ${ }^{[9]}$ The latter was used not only to image the molecular motor, but above all to trigger its rotation via the injection of tunneling electrons. Most importantly, it was discovered that the dissymmetric character of the rotor, with four phenyleneferrocenyl groups and a truncated tolyl arm, is of paramount importance. On the one hand, it allows a direct monitoring of the rotation (and of its direction) by following the position of the shorter arm, which serves as a tag. On the other hand, it was discovered that this dissymmetry induces a reversible behaviour, with a direction of rotation which depends on the location of the tip during the pulse (above one of the longer ferrocenyl-appended arms, or above the shorter truncated arm).

This motor belongs to a broader family of motors that have been reported along the years (Figure 1). ${ }^{[12]}$ This family mostly involves $C_{5}$-symmetric rotors, with arms of various lengths and nature. ${ }^{[11,13]}$ Indeed, while the dissymmetric motor $\mathbf{1}$ displays a diameter of about $2 \mathrm{~nm}$ with a single para-phenylene separating the cyclopentadienyl and ferrocenyl units, several motors with longer arms have been reported. These $C_{5}$-symmetric rotors included phenylethynyl linkers ${ }^{[13 \mathrm{~b}]}$ but also insulating groups such as bisethynyl trans-platinum(II $)^{[13 b]}$ or bicycloocty ${ }^{[13 c]}$ spacers. Moreover, most of the motors had been originally designed to be deposited on insulating oxide surfaces and therefore display ester anchoring groups. 

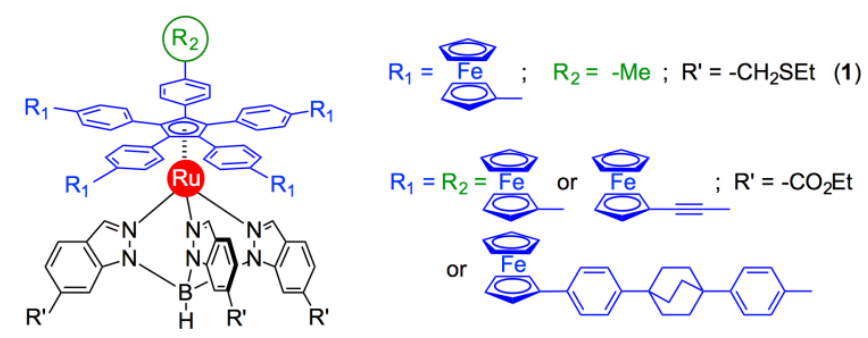

Figure 1. Structure of the unidirectional and reversible tetraferrocenyl molecular motor 1 and of symmetric Ru(II)-based molecular motors incorporating ester anchoring groups on the scorpionate ligand, and arms of various lengths and nature connected to the cyclopentadienyl core.

However, the technology is currently not mature enough to address horizontally an electron-fueled rotary motor located between two electrodes on an insulating surface (i.e. a nanojunction). Our efforts are thus currently focused on the development of new symmetric and dissymmetric structures of motors and gears, ${ }^{[12 b, c]}$ specifically designed for an optimal interaction with metallic surfaces such as gold (Scheme 1).
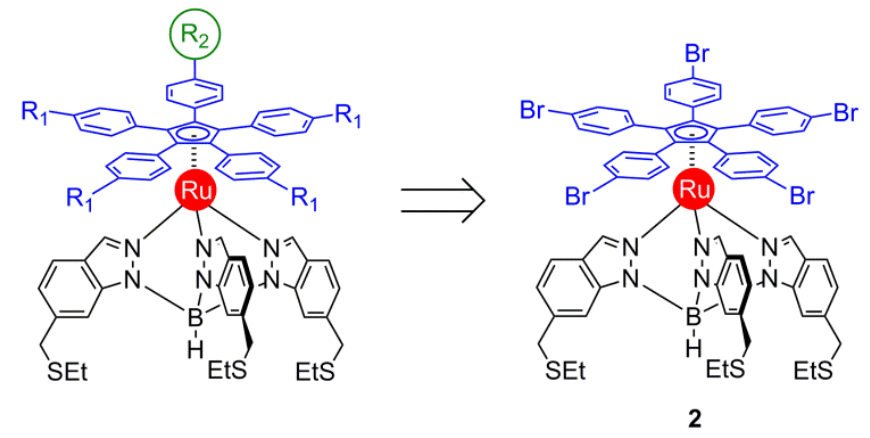

Scheme 1. Structure of symmetric $\left(R_{1}=R_{2}\right)$ or dissymmetric $\left(R_{1} \neq R_{2}\right)$ molecular motors and gears, and related retrosynthetic analysis leading back to common key intermediate 2 .

From a retrosynthetic point of view, all the structures including a $C_{5}$-symmetric rotor stem from key intermediate 2, displaying aryl bromide functions on each arm, ready for various cross-coupling reactions. This strategy was successfully applied to the synthesis of our family of symmetric motors, starting from pentaphenylcyclopentadiene (Scheme 2). ${ }^{[1]}$ The latter is first brominated on the phenyl para-positions and on the cyclopentadiene core using neat bromine giving an hexabrominated compound (3) in a nearly quantitative yield. Subsequent oxidative addition on ruthenium(0) cluster $\mathrm{Ru}_{3}(\mathrm{CO})_{12}$ leads to complex $4{ }^{[14]}$ in accordance with the method reported by Connelly and Manners. ${ }^{[15]}$ Conversion of this piano-stool complex into the key intermediate $\mathbf{2}$ is finally achieved via ligand exchange in the presence of the potassium salt of thioether-functionalized hydrotris(indazolyl)borate (5.K). Although this synthetic route suffers from the low yield of the last step, it allows the formation of the cyclopentadienyl-Ru(II) complex, which appeared impossible under other tested conditions due to the strong steric hindrance of the five phenyl rings attached to the cyclopentadienyl core. 


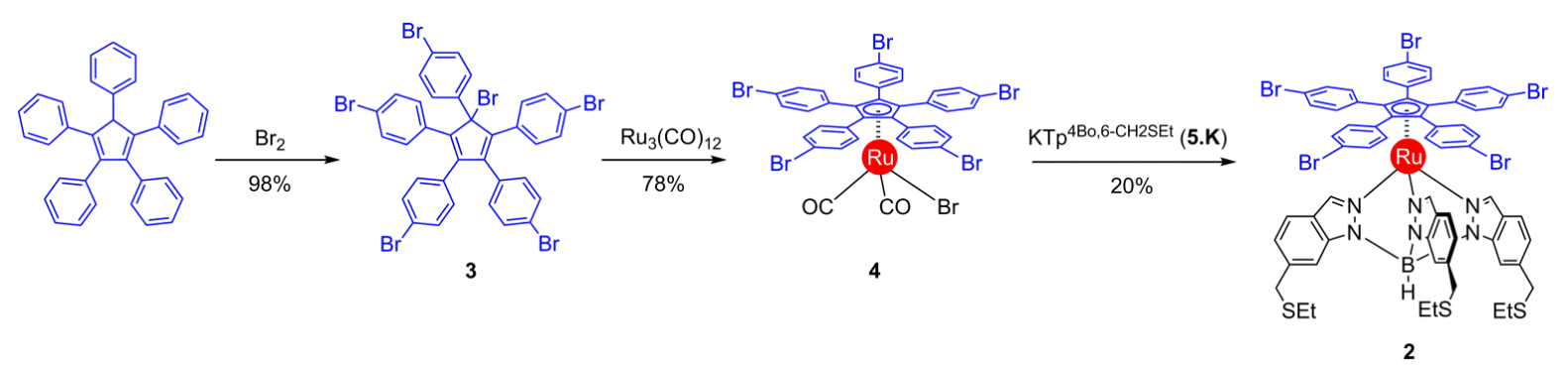

Scheme 2. Synthesis of key intermediate 2 starting from pentaphenylcyclopentadiene.

By contrast, the synthesis of the dissymmetric motor 1 (with $R_{1}=F c$ and $R_{2}=M e$ ) involved the introduction of the tolyl group corresponding to the truncated arm at a very early stage. ${ }^{[1]}$ In addition to an evident lack of modularity, it was observed that the oxidative addition of the dissymmetric cyclopentadienyl bromide on the $\mathrm{Ru}_{3}(\mathrm{CO})_{12}$ cluster was less efficient (43\%) than with the corresponding symmetric precursor 3 (78\%). This tendency was confirmed by other attempts with cyclopentadienyl bromides involving one longer and potentially coordinating arm. ${ }^{[16]}$ In view of future developments of dissymmetric motors and gears based on the ruthenium cyclopentadienyl scaffold, the latter approach is not reliable and modular enough. It is thus envisioned to exploit penta-bromide key intermediate $\mathbf{2}$ and perform a first statistical single cross-coupling to generate the differentiated arm. The remaining four activated positions could then undergo cross-couplings reactions to yield various dissymmetric rotors.

This renewed strategy towards dissymmetric motors and gears highlights the need for important amounts of key intermediate 2. It thus appeared necessary not only to increase the efficiency of the coordination of the tripodal ligand (only $20 \%$, Scheme 2) but also to optimize the synthesis of potassium hydrotris[6((ethylsulfanyl)methyl)indazolyl]borate $\mathbf{5 . K}$ by itself. The latter is a bifunctional platform combining anchoring groups and coordinating sites pointing in opposite directions. The anchoring groups are necessary to efficiently restrict the possible translation, rotation and rocking motions of molecules on a surface. While a single binding point only prevents translation motions and a second one additionally blocks the rotation of the molecule, a minimum of three points of anchoring are necessary to preclude rocking motion. In our design, the rigid hydrotris(indazolyl)borate scaffold bears three functional thioether pendant groups well oriented at the 6-position of the indazole core to very efficiently immobilize this platform on metallic surfaces such as gold, silver or copper (Scheme 1). On the opposite side of the ligand, three nitrogen atoms belonging to the indazole cores are available to coordinate a metal center such as ruthenium. This tripodal chelating unit thus allows the covalent binding of coordination complexes on a surface, as in the surface-mounted molecular gears or motors reported previously. ${ }^{[12]}$ Furthermore, lifting the metallic center away from the surface allows minimizing interferences caused by metal-surface interactions. In this context, rotors (in the case of rotary motors) or cranked wheels (in the case of gears) can be efficiently deposited, anchored and studied without almost any interaction with the surface, which is particularly important for Scanning Probe Microscopy experiments.

Herein we present our results towards higher efficiency and step-economy in the preparation of tripodal ligand $\mathbf{5}$ and of the ruthenium penta-bromide derivative $\mathbf{2}$, which serves as a central platform in the modular synthesis of various molecular motors and gears. As an application, the synthesis of a new symmetric penta-ferrocenyl motor with three thioether pendant groups (Scheme $1, R_{1}=R_{2}=$ ferrocene) is reported. 


\section{Results and Discussion}

As mentioned above, one of our aims was to optimize the synthetic route towards hydrotris(indazolyl)borate $\mathbf{5}$ in terms of efficiency and reproducibility. Indeed, the preparation of such scorpionate ligand involved 7 steps starting from 3-amino-4-methylbenzoic acid (Scheme 3). ${ }^{[1]}$ The latter was almost quantitatively protected as an ethyl ester and subsequently converted to the $1 \mathrm{H}$ indazole 8 by a Jacobson reaction followed by acidic hydrolysis of the intermediate acetamide 7 (64\% over two steps). Functional group manipulation to convert the ethyl ester into the desired ethyl thioether then involved the reduction of the ester to the corresponding alcohol $\mathbf{9}$, bromination and subsequent nucleophilic substitution with ethanethiol. The thioether-appended $1 H$-indazole $\mathbf{1 0}$ was finally reacted with $\mathrm{KBH}_{4}$ under solvent-free conditions at $200{ }^{\circ} \mathrm{C}$ to afford selectively the potassium hydrotris(indazolyl)borate $\mathrm{KTp}^{4 \mathrm{Bo}, 6-\mathrm{CH} 2 \mathrm{SEt}}(\mathbf{5 . K})$ which was purified by sublimation of unreacted indazole 10.

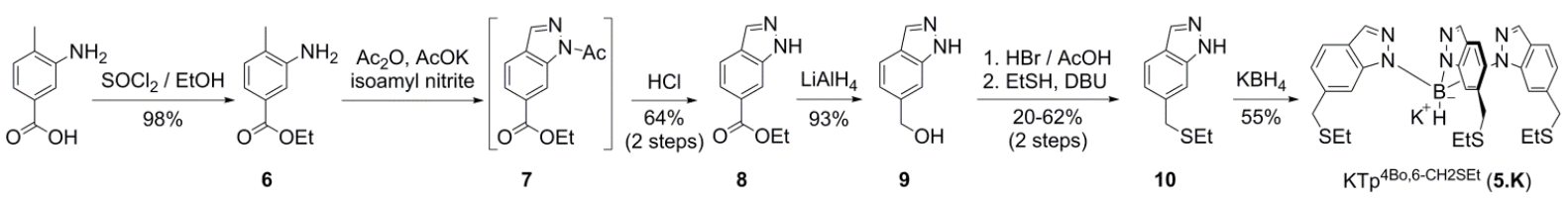

Scheme 3. Synthetic route toward the potassium salt of hydrotris(indazolyl)borate 5.K, starting from 3amino-4-methylbenzoic acid.

This synthetic sequence has been intensely used in our group as a standard way to prepare indazolederived scorpionate ligands carrying either ester (from a direct reaction between $\mathrm{KBH}_{4}$ and $\mathbf{8}$ ) or thioether anchoring groups. Now that our main interest lies in molecular machines to be studied on metallic surfaces, it was desirable to renew the synthetic route towards thioether-appended indazole 10, especially as a lack of efficiency and reproducibility of the ethanethiol-mediated nucleophilic substitution was observed throughout the years.

\section{Improved synthetic route to thioether-appended indazoles}

Interestingly, Sakai et al. recently reported the direct conversion of esters into sulfides via an indiumcatalyzed reductive sulfidation reaction (Scheme 4). ${ }^{[18]}$ The ester is directly reacted with the appropriate thiol in 1,2-dichloroethane (1,2-DCE) in the presence of a catalytic amount of indium(III) iodide as Lewis acid and an excess of 1,1,3,3-tetramethyldisiloxane (TMDS) as reducing agent. ${ }^{[19]}$ After overnight heating, thioethers deriving from aliphatic and aromatic esters and thiols are obtained in good to excellent yields.

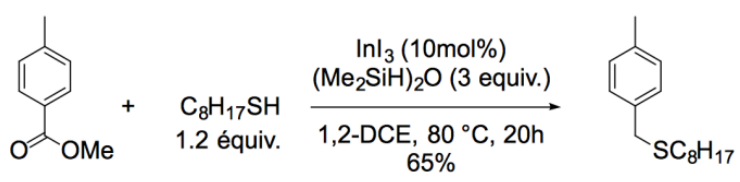

Scheme 4. Example of the indium(III)-catalyzed reductive sulfidation of methyl p-methylbenzoate with 1-octanethiol, as reported by Sakai et al. ${ }^{[18]}$ 
This method is thus of high synthetic utility since it avoids the common sequence involving the reduction of the ester, subsequent conversion of the alcohol into a (pseudo)halide and final substitution by a sulfur nucleophile.

The efficiency and the scope of this transformation drew our attention since this would allow the direct conversion of indazolyl ester $\mathbf{8}$ to thioether $\mathbf{1 0}$ (Scheme 3) in a single step (instead of three), although Sakai et al. did not mention any test on heteroaromatic derivatives.

In order to prevent the coordination of free $1 H$-indazole to the $\mathrm{In}(\mathrm{III})$ center, the reaction was first tested with the $N$-acetyl-protected indazolyl ester 7. When reproducing the conditions reported by Sakai et al., i.e. $10 \mathrm{~mol} \%$ indium(III) iodide in combination with ethanethiol (1.2 equiv.) and 1,1,3,3tetramethyldisiloxane (TMDS, 3 equiv. i.e. $6 \mathrm{Si}$ - $\mathrm{H}$ equiv.) in 1,2-dichloroethane at $60{ }^{\circ} \mathrm{C}$ for $20 \mathrm{~h}$, a complex mixture was obtained as observed by ${ }^{1} \mathrm{H}$ NMR spectroscopy of the crude product (Table 1 , entry 1). Careful analysis revealed the presence of traces amounts of unconverted starting material (7). Since no further signal corresponding to an acetamide moiety was detected, it was concluded that the expected $\mathrm{N}$-acetyl protected indazole carrying the ethyl thioether function had not been formed. To our delight, it appeared that the free $1 \mathrm{H}$-indazole scaffold bearing the thioether function was present in the mixture, although in traces amounts. This indicates that the desired reductive sulfidation takes place, although with a concomitant deprotection of the $\mathrm{N}$-acetyl group which most probably consumes both the thiol and the silane. Indeed, increasing the quantity of thiol and silane to 2.2 and 6 equivalents, respectively, the free $1 \mathrm{H}$-indazole $\mathbf{1 0}$ was gratifyingly formed as major product and isolated in 57\% yield (entry 2). To check if the possible coordination of the free $1 \mathrm{H}$-indazolyl ester $\mathbf{8}$ or thioether $\mathbf{1 0}$ formed during the reaction might deactivate the indium(III) catalyst and thus hamper the reaction, indium(III) iodide was introduced in slight excess (1.1 equivalent) compared to the substrate (entry 3 ). Under otherwise unchanged conditions, only a minor improvement of the isolated yield was obtained $(65 \%)$. In this reaction, a by-product (13) was formed in a ratio of 1:4 compared to product $\mathbf{1 0}$ according to the ${ }^{1} \mathrm{H}$ NMR spectrum of the crude mixture. This by-product had already been observed in various amounts under catalytic conditions and corresponds to the $N$-ethyl derivative of $\mathbf{1 0}$. The $N$-ethyl moiety in 13 most probably results from a direct reduction of the acetamide group, as already reported under similar conditions. ${ }^{[20]}$ To overcome this unproductive side reaction, the quantity of nucleophile was increased to 4 equivalents and the desired free $1 H$-indazole $\mathbf{1 0}$ was obtained as a single product in $86 \%$ yield (entry 4). Finally, in view of the synthesis of scorpionate ligands on a large scale, the same reaction was run on $1.5 \mathrm{~g}$ (compared to $150 \mathrm{mg}$ in entries 1-4) to give rise to thioether indazole 10 in a comparable $85 \%$ isolated yield (entry 5 ). 
Table 1. Optimization of the reaction conditions for the direct conversion of indazolyl ester 7 to thioether $10,{ }^{[a]}$ in one single step instead of four.

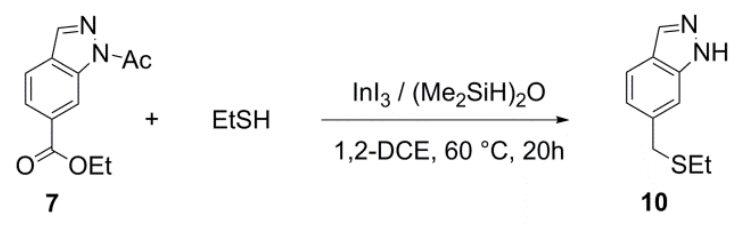

\begin{tabular}{lllll}
\hline Entry & $\begin{array}{l}\mathrm{InI}_{3} \\
\text { (equiv.) }\end{array}$ & $\begin{array}{l}\text { EtSH } \\
\text { (equiv.) }\end{array}$ & $\begin{array}{l}\left(\mathrm{Me}_{2} \mathrm{SiH}\right)_{2} \mathrm{O} \\
(\text { equiv. })\end{array}$ & $\begin{array}{l}\text { Yield } \\
(\%)^{[\mathrm{b}]}\end{array}$ \\
\hline 1 & 0.1 & 1.2 & 3 & Traces \\
2 & 0.1 & 2.2 & 6 & $57^{[\mathrm{c}]}$ \\
3 & 1.1 & 2.2 & 6 & $65^{[\mathrm{c}]}$ \\
4 & 1.1 & 4 & 6 & 86 \\
$5^{[\mathrm{d}]}$ & 1.1 & 4 & 6 & 85 \\
\hline
\end{tabular}

[a] The reactions were run on a $150 \mathrm{mg}(0.65 \mathrm{mmol})$ scale unless otherwise stated. [b] Isolated yield unless otherwise stated. [c] Byproduct $\mathbf{1 3}$ resulting from the direct reduction of the $\mathrm{N}$-acetyl group into an $\mathrm{N}$-ethyl moiety was detected in the crude mixture. [d] The reaction was run on a $1.5 \mathrm{~g}(6.5 \mathrm{mmol})$ scale.

Application of the reaction conditions for the reductive sulfidation of esters developed by Sakai et al. and subsequent optimization now allow for a direct conversion of $\mathrm{N}$-acetyl indazolyl ester $\mathbf{7}$ into the corresponding $\mathrm{N}$-deprotected indazolyl thioether $\mathbf{1 0}$ in high yield and in a single step. This one-pot deprotection / reductive sulfidation not only shortens the synthetic route towards tripodal ligand $\mathbf{5 . K}$ but also avoids the tedious isolation of $1 H$-indazolyl ester $\mathbf{8}$. The thioether-functionalized indazole (10) is now very conveniently prepared in three steps on the gram scale starting from 3-amino-4-methylbenzoic acid in a reproducible 70\% overall yield (Scheme 5), instead of six steps and a non-reproducible overall yield of 12 to $36 \%$ previously.
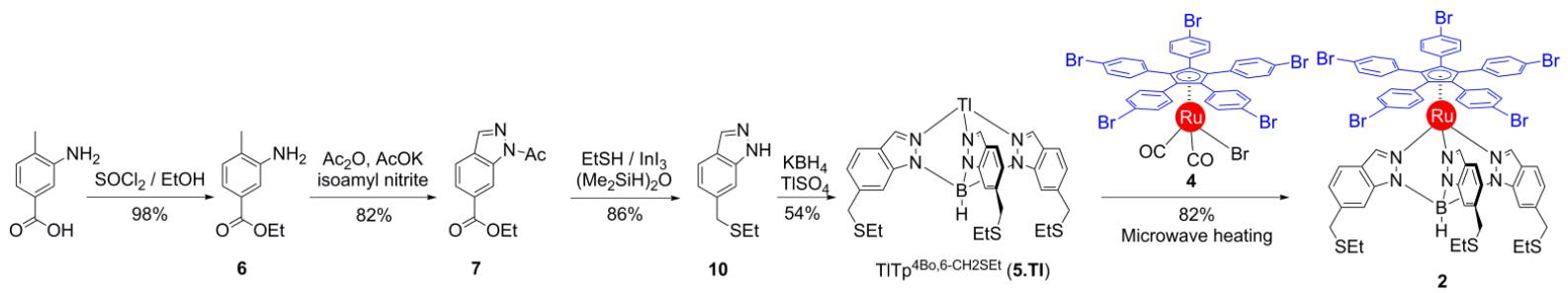

Scheme 5. Optimized synthetic route yielding the key penta-bromide rotor 2 in 5 steps and $31 \%$ overall yield in the longest linear sequence (instead of 8 steps and maximum $4 \%$ yield previously).

Following this improvement, the reproducibility of the synthesis of the hydrotris(indazolyl)borate salt 5.K and the efficiency of the subsequent ligand exchange to yield key intermediate $\mathbf{2}$ were tackled. 
Beneficial use of the thallium salt of the tripodal ligand as intermediate in the synthesis of rotor 2

Hydrotris(pyrazolyl)borates and by extension hydrotris(indazolyl) borates, are mostly prepared by heating an excess of the appropriate pyrazole (respectively indazole) with $\mathrm{KBH}_{4}$ or $\mathrm{NaBH}_{4}$ under neat conditions, as described above for the synthesis of the potassium salt 5.K. ${ }^{[21]}$ However, the thallium(I) salts of such derivatives have appeared as mild and valuable reagents for the transfer of the scorpionate ligands onto various transition metals, as they exhibit a lower reducing ability than the corresponding alkali metal salts. ${ }^{[2]}$ The crystallinity of the thallium(I) complexes also renders their isolation more easy, and we thus envisioned the synthesis of the thallium salt TITp ${ }^{4 \mathrm{Bo}, 6-\mathrm{CH} 2 \mathrm{SEt}} \mathbf{5 . T I}$. The thallium salts of scorpionate ligands are usually obtained by cation exchange, reacting the alkali metal salt with $\mathrm{TINO}_{3}$. In 2008, two new methods were reported by Kitamura et al.: i) preparation and isolation of thallium borohydride $\mathrm{TlBH}_{4}$ and subsequent reaction with pyrazole or indazole derivatives ${ }^{[23]}$ or ii) a solvent-free one-pot method using $\mathrm{KBH}_{4}$ and $\mathrm{Tl}_{2} \mathrm{SO}_{4}$ in a 2:1 ratio to yield the thallium hydrotris(pyrazolyl)- or hydrotris(indazolyl)borate via an in-situ cation exchange. ${ }^{[24]}$ Given the toxicity of thallium(I), the latter one-pot procedure was selected to avoid the isolation of the thallium borohydride reagent. Indazole $\mathbf{1 0}$ was thus reacted in the presence of potassium borohydride and thallium sulfate to give rise to thallium hydrotris(indazolyl)borate 5.Tl in 54\% yield (Scheme 5). Generating the thallium salt instead of the potassium salt leads to a comparable yield (54\% vs 55\%, respectively) but avoids the tedious and nonreproducible sublimation procedure as the thallium salt is efficiently recrystallized. However, the main advantage of using the thallium intermediate 5.Tl lies in the ligand exchange step. Indeed, the reaction of 2 equivalents of thallium hydrotris(indazolyl)borate 5.Tl with 1 equivalent of the ruthenium cyclopentadienyl complex 4 in THF at $100{ }^{\circ} \mathrm{C}$ for $48 \mathrm{~h}$ afforded the target compound 2 in $67 \%$ yield, compared to $20 \%$ with the potassium salt 5.K under otherwise similar conditions (Scheme 2). To our delight, the efficiency of this reaction was even further increased to $82 \%$ replacing classical heating with microwave heating $\left(100{ }^{\circ} \mathrm{C}, 3 \times 10 \mathrm{~min}\right)$ in acetonitrile as solvent (Scheme 5).

The indium(III)-mediated one pot deprotection / reductive sulfidation sequence followed by the preparation of the thallium salt of the scorpionate ligand has significantly shortened the synthetic route to the penta-bromide rotor $\mathbf{2}$ and increased its efficiency. Indeed, this key building block towards molecular motors and gears is now prepared in 5 steps in $31 \%$ overall yield in the longest linear sequence, compared to 8 steps and a maximum $4 \%$ overall yield formerly.

\section{Extension of the indium(III)-mediated methodology to the synthesis of ester-appended scorpionate ligands}

During our work towards the reductive sulfidation of indazolyl ester 7, it was observed that the deprotection of the $\mathrm{N}$-acetylindazole to give the corresponding $1 \mathrm{H}$-indazole $\mathbf{8}$ occurs prior to the effective transformation of the ester. Deprotection of the $N$-acetyl protecting group is most commonly performed under drastic basic (hydroxide, alkoxide) or acidic $(\mathrm{HCl})$ conditions, ${ }^{[25,26]}$ provided that these conditions are compatible with additional functional groups. For instance, in our synthetic route towards hydrotris(indazolyl)borates, the crude $N$-acetylindazole obtained via the Jacobson reaction was deprotected using concentrated $\mathrm{HCl}$ at $60^{\circ} \mathrm{C}$ (Scheme 3). The $1 H$-indazole 8 was obtained in a moderate $64 \%$ yield over two steps, and it was observed that a significant amount of product was lost during the acidic deprotection step, possibly via hydrolysis of the ester. 
Since the amide function appears more reactive than the ester towards In(III)/TMDS/EtSH reaction conditions, the possible selective deprotection of the indazole core under mild conditions was investigated.

Table 2. Screening of conditions for the $N$-deprotection of $N$-acetylindazole 7 and corresponding blank experiments. ${ }^{[a]}$

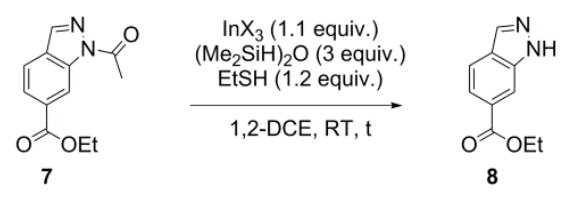

\begin{tabular}{lllll}
\hline Entry & $\mathrm{InX}_{3}$ & $\mathrm{t}(\mathrm{h})$ & Conv. $(\%)^{[\mathrm{b}]}$ & ${\text { Yield }(\%)^{[\mathrm{c}]}}^{[\mathrm{d}]}$ \\
\hline 1 & $\mathrm{InI}_{3}$ & 16 & 100 & $28^{\mathrm{d}]}$ \\
2 & $\mathrm{In}(\mathrm{OAc})_{3}$ & 4 & 0 & - \\
3 & $\mathrm{In}(\mathrm{OTf})_{3}$ & 4 & 5 & $\mathrm{nd}^{[\mathrm{e}]}$ \\
4 & $\mathrm{InCl}_{3}$ & 20 & 91 & $\mathrm{nd}$ \\
5 & $\mathrm{InCl}_{3}$ & 48 & 100 & 96 \\
$7^{[\mathrm{f}]}$ & - & 48 & 0 & - \\
$8^{[\mathrm{h}]}$ & $\mathrm{InCl}_{3}$ & 48 & $96^{[\mathrm{g}]}$ & 5 \\
\hline
\end{tabular}

[a] The reactions were run on a $150 \mathrm{mg}$ scale (entries 1-5) or on a $75 \mathrm{mg}$ scale (entries 6-8). [b] Conversion of the starting material 7 as determined by ${ }^{1} \mathrm{H}$ NMR spectroscopy. [c] Isolated yield. [d] The desired product 8 was formed along with reductive sulfidation product $\mathbf{1 0}$ (13\% isolated yield) and other unidentified products, as observed by ${ }^{1} \mathrm{H}$ NMR spectroscopy of the crude product. [e] Not determined. [f] Ethanethiol was omitted. [g] $\mathrm{N}$ ethylindazolyl ester $\mathbf{1 4}$ and the desired product $\mathbf{8}$ were obtained in the crude mixture, in a 2:1 ratio. [h] 1,1,3,3-Tetramethyldisiloxane was omitted.

In a first test, the slight excess of indium(III) iodide (1.1 equiv.) was maintained while the amounts of ethanethiol and TMDS were reduced to 1.2 and 3 equiv. respectively, in order to favor the single reaction of the amide function (Table 2, entry 1). After 16h at room temperature, the starting material was fully converted but a mixture of products was obtained, including $\mathbf{1 0}$ resulting from the $\mathrm{N}$-deprotection / reductive sulfidation sequence. The desired deprotected indazolyl ester $\mathbf{8}$ was isolated in $28 \%$ yield. Less reactive indium(III) species were tested next in order to avoid the conversion of the ester moiety. In the presence of indium(III) acetate and triflate, the conversion was very low after $4 \mathrm{~h}$ at room temperature (entries 2 and 3). Conversely, indium(III) chloride promoted a smooth reaction with 91\% conversion of the starting material after $20 \mathrm{~h}$ (entry 4). Increasing the reaction time to $48 \mathrm{~h}$ led to full conversion and the desired deprotected $1 H$-indazole 8 was isolated in a satisfactory $96 \%$ yield (entry 5 ). Blank experiments were next carried out in order to assess the role of each reagent. As expected, omission of the Lewis acidic indium(III) species totally prevented the reaction (entry 6). In the absence 
of thiol, the major product was $N$-ethylindazolyl ester (14), resulting from the complete reduction of the carbonyl moiety to the corresponding methylene (entry 7). ${ }^{[20]}$ Finally, the reducing agent is also crucial in this procedure as no reaction occurs in the absence of hydrosilane (entry 8). It is thus assumed that this deprotection reaction is formally a reductive sulfidation of the acetamide moiety, with the indazole core playing the role of the leaving group.

With these new deprotection conditions in hand, indazolyl ester $\mathbf{8}$ is now efficiently synthesized in $79 \%$ overall yield starting from 3-amino-4-methylbenzoic acid (Scheme 6), as compared to the 63\% obtained previously (Scheme 3). The preparation of ester-appended hydrotris(indazolyl)borate 11.K, used as stator in studies on insulating surfaces, will benefit from this improvement implying an increase from $43 \%$ to $54 \%$ of the overall yield on this four-step sequence.

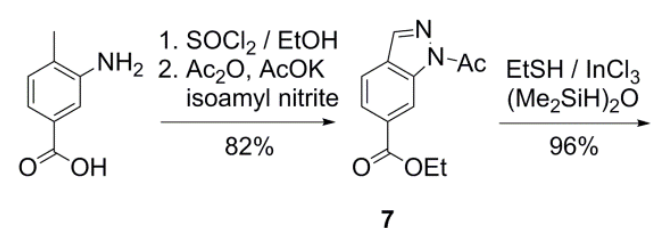

7

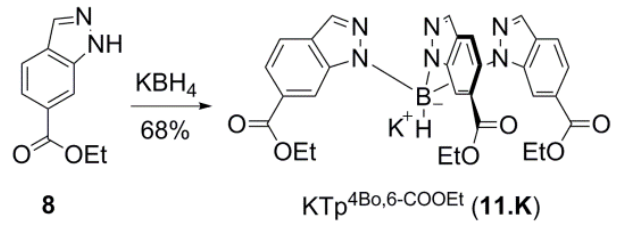

Scheme 6. Optimized synthetic route towards the potassium salt of ester-functionalized hydrotris(indazolyl)borate 11.K.

\section{Test-reaction: Synthesis of a new molecular motor and last major improvement using microwave activation}

So as to probe the efficiency of a complete synthetic sequence up to molecular machines, the preparation of the new molecular motor $\mathbf{1 2}$ incorporating a symmetric rotating subunit was tackled (Scheme 7).

The penta-bromide rotor 2, displaying a thioether-functionalized tripodal ligand, was submitted to Suzuki-Miyaura coupling conditions in the presence of a large excess of ferroceneboronic acid, using palladium diacetate / SPhos as catalytic system, potassium phosphate as base in anhydrous toluene. Penta-aryl bromide 2 thus underwent five successive Suzuki-Miyaura couplings to give rise to the desired penta-ferrocenyl molecular motor 12 in $17 \%$ yield after $48 \mathrm{~h}$ at $100{ }^{\circ} \mathrm{C}$ (Scheme 7, classical heating).

Considering the future preparation of motors and gears that may involve more complex and expensive boronic acid derivatives, decreasing the amount of such partner was highly desirable. New reaction conditions were thus developed, involving 7.5 equiv. of ferroceneboronic acid (i.e. 1.5 equiv. per aryl bromide), sodium tert-butylate (22.5 equiv.) as base and [1,1'-bis (diphenylphosphino)ferrocene]dichloropalladium $\mathrm{PdCl}_{2}$ (dppf) (20 mol\% per aryl bromide) as catalyst in anhydrous toluene. Microwave heating at $135{ }^{\circ} \mathrm{C}$ for $1 \mathrm{~h}$ gave rise to the desired penta-ferrocenyl product in a highly satisfactory $45 \%$ yield (Scheme 7 , microwave heating). This step leads to the formation of five new C-C bonds in a single synthetic operation, with a yield of $85 \%$ per Suzuki-Miyaura cross-coupling in spite of the steric hindrance. These new coupling conditions now allow an expedient synthesis of this symmetric molecular motor, displaying short ferrocenylphenylene arms, in 6 steps in the longest linear sequence with an overall yield of $14 \%$. 


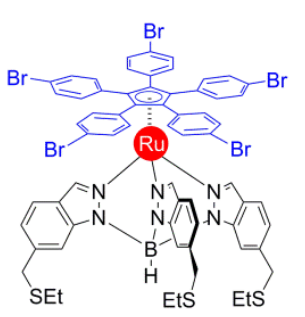

2

$\mathrm{FcB}(\mathrm{OH})_{2}$ (40 equiv.), $\mathrm{Pd}(\mathrm{OAc})_{2} / \mathrm{SPhos}, \mathrm{K}_{3} \mathrm{PO}_{4}$ classical heating, $100^{\circ} \mathrm{C}, 48 \mathrm{~h}$

$\mathrm{FcB}(\mathrm{OH})_{2}\left(7.5\right.$ equiv.), $\mathrm{PdCl}_{2}$ (dppf), ${ }^{t} \mathrm{BuONa}$ $\mathrm{MW}, 135^{\circ} \mathrm{C}, 1 \mathrm{~h}$

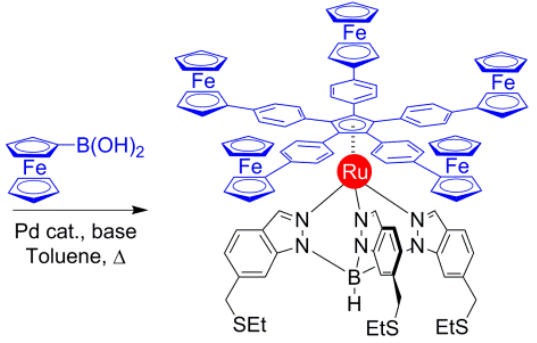

12

$17 \%$

$45 \%$

Scheme 7. Synthesis of the new molecular motor 12 via a five-fold Suzuki-Miyaura cross-coupling under classical or microwave heating.

The new molecular motor $\mathbf{1 2}$ was fully characterized and exhibits free rotation at room temperature as shown by NMR spectroscopy. Its properties will be investigated by Scanning Probe Microscopy techniques in the near future.

\section{Conclusions}

In this work, high efficiency and step-economy was achieved in the preparation of thioetherfunctionalized hydrotris(indazolyl) borates to be used as anchoring platforms in surface-mounted rotary molecular machines, but also as a general platform to anchor various metallic centers on gold, silver or copper surfaces. Indeed, the development of a one-pot " $N$-deprotection/ ester reductive sulfidation" sequence allowed the direct conversion of the $N$-acetylindazolyl ester precursor into the corresponding $1 H$-indazolyl thioether in a single high-yielding step mediated by indium(III) iodide. The thioetherfunctionalized indazole is now very conveniently prepared in three steps on the gram scale starting from 3-amino-4-methylbenzoic acid in a reproducible $70 \%$ overall yield, instead of six steps and a nonreproducible overall yield of 12 to $36 \%$ previously. Furthermore, milder conditions involving indium(III) chloride and the same TMDS/EtSH system were identified for the selective cleavage of the $\mathrm{N}$-acetyl protecting group leading to the free $1 \mathrm{H}$-indazolyl ester in excellent yield, which is of interest for the synthesis of ester-appended scorpionate ligands.

In view of the synthesis of families of ruthenium(II) complexes based on a thioether-functionalized stator and a penta-aryl cyclopentadienyl rotor, the preparation of the penta(4bromophenyl)cyclopentadienyl common intermediate was improved to reach $31 \%$ overall yield in the longest linear sequence (5 steps), instead of a maximum of $4 \%$ (over 8 steps) previously. A five-fold Suzuki-Miyaura cross-coupling of this key precursor gave rise to a new $C_{5}$-symmetric molecular motor with five ferrocenylphenylene arms, proving that molecular machines can now be obtained efficiently in 6 steps via our renewed synthetic route. The modular synthesis of various symmetric and dissymmetric molecular gears, exploiting the same synthetic strategy, is now underway. 


\section{Experimental Section}

\section{General methods:}

All commercially available chemicals were of reagent grade and were used without further purification. Isoamyl nitrite, anhydrous 1,2-dichloroethane, anhydrous THF, anhydrous acetonitrile, anhydrous toluene, ethanethiol, potassium phosphate and sodium tert-butoxide were purchased from Aldrich. 3Amino-4-methylbenzoic acid, potassium borohydride, thallium(I) sulfate and 1,1'bis(diphenylphosphino)ferrocenepalladium(II) dichloride (dichloro-methane adduct) $\mathrm{Pd}(\mathrm{dppf}) \mathrm{Cl}_{2} \cdot \mathrm{CH}_{2} \mathrm{Cl}_{2}$ were purchased from Acros. Trichloroindigane, triiodoindigane and ferroceneboronic acid were purchased from Alfa Aesar. 1,1,3,3-Tetramethyldisiloxane and palladium(II) acetate were purchased from ABCR. Potassium acetate was purchased from Lancaster, acetic anhydride from Fluka and 2-dicyclohexylphosphino-2'-6'-dimethoxybiphenyl (SPhos) from TCI. Compounds $3{ }^{[14]} \mathbf{4},{ }^{[14]} \mathbf{6},{ }^{[17]}$ and 11.K ${ }^{[17]}$ were prepared according to the corresponding published procedures. All reactions were carried out using standard Schlenk techniques under an argon atmosphere. Thin layer chromatography (TLC) was performed on pre-coated aluminum-backed silica gel $60 \mathrm{UV}_{254}$ plates (Macherey-Nagel) with visualization effected using ultraviolet irradiation $(\square=254$, $366 \mathrm{~nm}$ ). Flash column chromatography was carried out on 230-400 mesh silica gel (Aldrich) unless otherwise stated. Microwave reactions were carried out using CEM Discover LabMate. NMR, IR and mass spectra were recorded by the appropriate services of the Toulouse Institute of Chemistry (ICT FR2599). NMR spectra were recorded with a Bruker Avance 300 or Avance 500 spectrometer and full assignments were made with the assistance of COSY, HMBC and HSQC spectra when necessary. ${ }^{1} \mathrm{H}$ and ${ }^{13} \mathrm{C}$ NMR chemical shifts $(\delta)$ are reported in ppm relative to the signal of tetramethylsilane (TMS). Residual solvent signals were used as an internal reference. Coupling constants $(J)$ are given in $\mathrm{Hz}$ and the following abbreviations have been used to describe the signals: singlet (s); doublet (d); triplet (t); quadruplet (q); quintuplet (quint); multiplet (m). The numbering system used for the assignment of signals in new compounds $\mathbf{5 . T l}, \mathbf{7}$ and $\mathbf{1 2}$ is provided in the supporting information document, along with the corresponding spectra. IR spectra were recorded with a Nicolet 6700 FTIR-ATR. Only selected characteristic peaks are recorded. High-resolution mass spectra (HRMS) were performed with a Waters GCT Premier spectrometer for desorption chemical ionization $\left(\mathrm{DCI} / \mathrm{CH}_{4}\right)$ and with a Waters Xevo $\mathrm{G} 2$ QTof spectrometer for electrospray ionization (ESI). Melting points were measured with a Krüss M5000 melting-point apparatus or with a Kofler hot bench and are uncorrected. UV/Vis spectra were recorded with a Shimadzu UV-26000 spectrometer (sh=shoulder, $\varepsilon\left[\mathrm{mol}^{-1} \mathrm{dm}^{3} \mathrm{~cm}^{-1}\right]$ is reported in parentheses).

\section{Compound 2:}

In a dry tube designed for microwave irradiation and under argon, compound 5.Tl (160 mg, $0.20 \mathrm{mmol}$, 2.0 equiv.), ruthenium(II) complex 4 (110 mg, $0.10 \mathrm{mmol}, 1.0$ equiv.) were introduced and degassed anhydrous acetonitrile $(4 \mathrm{~mL})$ was added. The tube was sealed and the reaction mixture was heated under microwave irradiation at $100{ }^{\circ} \mathrm{C}$ for $3 \times 10 \mathrm{~min}$. A pressure of 5 bar was achieved due to the $\mathrm{CO}$ evolution and this pressure was released between heating cycles. The completion of the reaction was monitored by TLC. The resulting mixture was diluted with $\mathrm{CH}_{2} \mathrm{Cl}_{2}$ and filtered through a pad of silica gel. The solvents were removed under reduced pressure and the residue was purified by column chromatography $\left(\mathrm{CH}_{2} \mathrm{Cl}_{2} /\right.$ cyclohexane gradient from 0:100 up to 30:70) to afford compound 2 (128 $\mathrm{mg}$, $0.08 \mathrm{mmol}, 82 \%)$ as an orange solid. $R_{\mathrm{f}}=0.3\left(\mathrm{CH}_{2} \mathrm{Cl}_{2} /\right.$ cyclohexane $\left.30: 70\right) ;{ }^{1} \mathrm{H} \mathrm{NMR}\left(300 \mathrm{MHz}, \mathrm{CD}_{2} \mathrm{Cl}_{2}\right.$, $\left.25^{\circ} \mathrm{C}\right): \delta=7.88(\mathrm{bs}, 3 \mathrm{H}), 7.80\left(\mathrm{~d},{ }^{4} J=0.5 \mathrm{~Hz}, 3 \mathrm{H}\right), 7.35\left(\mathrm{dd},{ }^{3} J=8.4 \mathrm{~Hz},{ }^{4} J=0.5 \mathrm{~Hz}, 3 \mathrm{H}\right), 7.21(\mathrm{~m}, 20 \mathrm{H})$, $7.04\left(\mathrm{dd},{ }^{3} \mathrm{~J}=8.4 \mathrm{~Hz},{ }^{4} \mathrm{~J}=1.4 \mathrm{~Hz}, 3 \mathrm{H}\right), 3.90(\mathrm{~s}, 6 \mathrm{H}), 2.46\left(\mathrm{q},{ }^{3} J=7.4 \mathrm{~Hz}, 6 \mathrm{H}\right), 1.27\left(\mathrm{t},{ }^{3} J=7.4 \mathrm{~Hz}, 9 \mathrm{H}\right)$; ${ }^{13} \mathrm{C}$ NMR $\left(125 \mathrm{MHz}, \mathrm{CD}_{2} \mathrm{Cl}_{2}, 25^{\circ} \mathrm{C}\right): \delta=143.6,140.2,137.8,135.1,132.1,130.6,122.3,122.0,121.9$, 120.0, 110.9, 87.1, 37.4, 25.3, 14.3; UV/Vis $\left(\mathrm{CH}_{2} \mathrm{Cl}_{2}\right): \lambda_{\max }(\varepsilon)=298$ (26800), $312 \mathrm{~nm}(25600$ $\mathrm{mol}^{-1} \mathrm{dm}^{3} \mathrm{~cm}^{-1}$ ); HRMS (ESI+): calcd for $\mathrm{C}_{65} \mathrm{H}_{54} \mathrm{BBr}_{5} \mathrm{~N}_{6} \mathrm{RuS}_{3}[\mathrm{MH}]^{+}: 1528.8674$, found: 1528.8652 . The data match those reported in the literature. ${ }^{[1]}$ 


\section{Thallium hydrotris\{6-[(ethylsulfanyl)methyl]indazol-1-yl\} borate (5.TI):}

6-[(Ethylsulfanyl)methyl]-1 $H$-indazole 10 (530 mg, 2.76 mmol, 3.0 equiv.), $\mathrm{KBH}_{4}(61 \mathrm{mg}, 1.11 \mathrm{mmol}$, 1.2 equiv.) and $\mathrm{Tl}_{2} \mathrm{SO}_{4}(285 \mathrm{mg}, 0.565 \mathrm{mmol}, 0.6$ equiv.) were successively placed in a dry Young-type Schlenk tube. The mixture was stirred at $140{ }^{\circ} \mathrm{C}$ for $1 \mathrm{~h}$ under an argon stream in an open system, and the Schlenk tube was then sealed and heated for $2 \mathrm{~h}$ at $180^{\circ} \mathrm{C}$. The mixture was allowed to cool to room temperature. The Schlenk tube was connected to an argon line, and the internal pressure, which had been raised by the evolution of hydrogen gas, was carefully released. Subsequent heating of the closed system during $3 \mathrm{~h}$ at $180{ }^{\circ} \mathrm{C}$ followed by cooling to room temperature yielded a white solid. Chloroform (10 $\mathrm{mL}$ ) was added and the resulting suspension was transferred to a conical centrifuge tube. After centrifugation at $3000 \mathrm{rpm}$ for $30 \mathrm{~min}$, the supernatant $(8 \mathrm{~mL})$ was separated and $8 \mathrm{~mL}$ of chloroform were added. The operation was repeated three times. The combined supernatants were evaporated to dryness. The residue was solubilized in a minimum amount of $\mathrm{CH}_{2} \mathrm{Cl}_{2}$, and $\mathrm{MeOH}$ was then added $(\mathrm{v} / \mathrm{v}$ $=1: 1)$. The thallium salt $\mathbf{5 . T l}$ crystallized by slow evaporation to give white crystals $(392 \mathrm{mg}, 0.496$ $\mathrm{mmol})$ in $54 \%$ yield. ${ }^{1} \mathrm{H}$ NMR $\left(300 \mathrm{MHz}, \mathrm{CD}_{2} \mathrm{Cl}_{2}, 25^{\circ} \mathrm{C}\right): \delta=8.05\left(\mathrm{~d},{ }^{4} \mathrm{~J}=0.8 \mathrm{~Hz}, 3 \mathrm{H}, \mathrm{H}_{\mathrm{a}}\right), 8.01(\mathrm{~m}, 3 \mathrm{H}$, $\left.\mathrm{H}_{\mathrm{d}}\right), 7.62\left(\mathrm{dd},{ }^{3} J=8.3 \mathrm{~Hz},{ }^{4} J=0.8 \mathrm{~Hz}, 3 \mathrm{H}, \mathrm{H}_{\mathrm{b}}\right), 7.11\left(\mathrm{dd},{ }^{3} J=8.3 \mathrm{~Hz},{ }^{4} J=1.4 \mathrm{~Hz}, 3 \mathrm{H}, \mathrm{H}_{\mathrm{c}}\right), 3.93(\mathrm{~s}, 6 \mathrm{H}$, $\left.\mathrm{H}_{\mathrm{e}}\right), 2.46\left(\mathrm{q},{ }^{3} \mathrm{~J}=7.4 \mathrm{~Hz}, 6 \mathrm{H}, \mathrm{H}_{\mathrm{f}}\right), 1.25\left(\mathrm{t},{ }^{3} \mathrm{~J}=7.4 \mathrm{~Hz}, 9 \mathrm{H}, \mathrm{H}_{\mathrm{g}}\right) ;{ }^{13} \mathrm{C} \mathrm{NMR}\left(75 \mathrm{MHz}, \mathrm{CD}_{2} \mathrm{Cl}_{2}, 25^{\circ} \mathrm{C}\right)$ : $\delta=144.9\left(\mathrm{C}_{2}\right), 137.6\left(\mathrm{C}_{1}\right), 133.5\left(\mathrm{C}_{5}\right), 122.7\left(\mathrm{C}_{7}\right), 122.5\left(\mathrm{C}_{4}\right), 121.0\left(\mathrm{C}_{3}\right), 112.4\left(\mathrm{C}_{6}\right), 37.0\left(\mathrm{C}_{8}\right), 25.7\left(\mathrm{C}_{9}\right)$, $14.7\left(\mathrm{C}_{10}\right)$; HRMS (ESI-): calcd for $\mathrm{C}_{30} \mathrm{H}_{34} \mathrm{BN}_{6} \mathrm{~S}_{3}$ [M-Tl] ${ }^{-}: 584.2136$, found: 584.2136.

\section{Ethyl 1-acetyl-1 $H$-indazole-6-carboxylate (7):}

A dry three-necked round bottom flask was successively charged with ethyl 3-amino-4-methylbenzoate 6 (2.0 g, $11.2 \mathrm{mmol}, 1.0$ equiv.), anhydrous toluene (50 mL), potassium acetate (1.1 g, $12.3 \mathrm{mmol}, 1.1$ equiv.) and acetic anhydride (3.8 mL, $40.5 \mathrm{mmol}, 3.6$ equiv.). Isoamyl nitrite (3.0 mL, $22.3 \mathrm{mmol}, 2.0$ equiv.) was then added dropwise over $15 \mathrm{~min}$. The resulting gelatinous mixture was stirred and heated at reflux for $16 \mathrm{~h}$ with a $15 \% \mathrm{NaOH}$ trap. The completion of the reaction was monitored by TLC. The solution was then evaporated to dryness to give an orange-brownish solid. The crude product was dissolved in $50 \mathrm{~mL}$ of $\mathrm{CH}_{2} \mathrm{Cl}_{2}$, filtered on a pad of silica gel and concentrated under reduced pressure. The residue was purified by column chromatography $\left(\mathrm{CH}_{2} \mathrm{Cl}_{2} /\right.$ pentane gradient from 30:70 up to 70:30) to give compound $7(2.1 \mathrm{~g}, 9.2 \mathrm{mmol})$ as an orange solid in $82 \%$ yield. $R_{\mathrm{f}}=0.6$ (ethyl acetate/cyclohexane 30:70); m.p. $95{ }^{\circ} \mathrm{C} ;{ }^{1} \mathrm{H}$ NMR (300 MHz, $\left.\mathrm{CDCl}_{3}, 25^{\circ} \mathrm{C}\right): \delta=9.07$ (m, $\left.1 \mathrm{H}, \mathrm{H}_{\mathrm{d}}\right), 8.15\left(\mathrm{~d},{ }^{4} \mathrm{~J}=0.9 \mathrm{~Hz}, 1 \mathrm{H}\right.$, $\left.\mathrm{H}_{\mathrm{a}}\right), 8.02\left(\mathrm{dd},{ }^{3} J=8.3 \mathrm{~Hz},{ }^{4} J=1.4 \mathrm{~Hz}, 1 \mathrm{H}, \mathrm{H}_{\mathrm{c}}\right), 7.75\left(\mathrm{dd},{ }^{3} J=8.3 \mathrm{~Hz},{ }^{4} J=0.8 \mathrm{~Hz}, 1 \mathrm{H}, \mathrm{H}_{\mathrm{b}}\right), 4.43\left(\mathrm{q},{ }^{3} J\right.$ $\left.=7.1 \mathrm{~Hz}, 2 \mathrm{H}, \mathrm{H}_{\mathrm{f}}\right), 2.80\left(\mathrm{~s}, 3 \mathrm{H}, \mathrm{H}_{\mathrm{e}}\right), 1.43\left(\mathrm{t},{ }^{3} \mathrm{~J}=7.1 \mathrm{~Hz}, 3 \mathrm{H}, \mathrm{H}_{\mathrm{g}}\right) ;{ }^{13} \mathrm{C} \mathrm{NMR}\left(75 \mathrm{MHz}, \mathrm{CDCl}_{3}, 25^{\circ} \mathrm{C}\right)$ : $\delta=171.0\left(\mathrm{C}_{8}\right), 166.3\left(\mathrm{C}_{10}\right), 139.4\left(\mathrm{C}_{1}\right), 138.8\left(\mathrm{C}_{2}\right), 131.5\left(\mathrm{C}_{5}\right), 129.0\left(\mathrm{C}_{7}\right), 125.5\left(\mathrm{C}_{3}\right), 120.7\left(\mathrm{C}_{4}\right), 117.2$ $\left(\mathrm{C}_{6}\right), 61.6\left(\mathrm{C}_{11}\right), 23.1\left(\mathrm{C}_{9}\right), 14.5\left(\mathrm{C}_{12}\right)$; IR (ATR): $\tilde{\mathrm{v}}=1715 \mathrm{~cm}^{-1}(\mathrm{C}=\mathrm{O})$; HRMS (DCI/CH$)$ : calcd for $\mathrm{C}_{12} \mathrm{H}_{13} \mathrm{~N}_{2} \mathrm{O}_{3}[\mathrm{MH}]^{+}: 233.0926$, found: 233.0935.

\section{Ethyl $1 H$-indazole-6-carboxylate (8):}

In a dry Schlenk tube under argon were successively added ethyl 1-acetyl- $1 H$-indazole-6-carboxylate 7 (150 mg, $0.65 \mathrm{mmol}, 1.0$ equiv.), trichloroindigane $\mathrm{InCl}_{3}(157 \mathrm{mg}, 0.71 \mathrm{mmol}, 1.1$ equiv.) and anhydrous 1,2-dichloroethane $(2 \mathrm{~mL})$. Ethanethiol $(60 \mu \mathrm{L}, 0.78 \mathrm{mmol}, 1.2$ equiv.) and 1,1,3,3tetramethyldisiloxane (TMDS) $(353 \mu \mathrm{L}, 1.94 \mathrm{mmol}, 3.0$ equiv.) were then successively added and the reaction mixture was stirred at room temperature for $16 \mathrm{~h}$. The completion of the reaction was monitored by TLC and the reaction medium was then evaporated to dryness. The crude product was dissolved in $\mathrm{CH}_{2} \mathrm{Cl}_{2}(10 \mathrm{~mL})$, transferred to a separatory funnel and water $(3 \mathrm{~mL})$ was added. The layers were separated and the aqueous phase was then extracted with $\mathrm{CH}_{2} \mathrm{Cl}_{2}(3 \times 5 \mathrm{~mL})$. The combined organic layers were dried over anhydrous $\mathrm{MgSO}_{4}$, filtered, and concentrated under reduced pressure. The crude material was purified by column chromatography (ethyl acetate/cyclohexane 1:1). to afford compound 8 (118 mg, $0.62 \mathrm{mmol}$ ) as a white solid in $96 \%$ yield. $R_{\mathrm{f}}=0.32$ (ethyl acetate/cyclohexane 30:70); m.p. $125^{\circ} \mathrm{C} ;{ }^{1} \mathrm{H}$ NMR $\left(300 \mathrm{MHz}, \mathrm{CDCl}_{3}, 25^{\circ} \mathrm{C}\right): \delta=10.25$ (br s, $\left.1 \mathrm{H}\right), 8.28(\mathrm{~m}, 1 \mathrm{H}), 8.15\left(\mathrm{~d},{ }^{4} J=0.8 \mathrm{~Hz}, 1 \mathrm{H}\right)$, 
$7.88\left(\mathrm{dd},{ }^{3} J=8.5 \mathrm{~Hz},{ }^{4} J=1.3 \mathrm{~Hz}, \mathrm{AB}\right.$ system, $\left.1 \mathrm{H}\right), 7.81\left(\mathrm{dd},{ }^{3} J=8.5 \mathrm{~Hz},{ }^{4} J=0.8 \mathrm{~Hz}\right.$, AB system, $\left.1 \mathrm{H}\right)$, 4.44 (q, $\left.{ }^{3} \mathrm{~J}=7.1 \mathrm{~Hz}, 2 \mathrm{H}\right), 1.44\left(\mathrm{t},{ }^{3} \mathrm{~J}=7.1 \mathrm{~Hz}, 3 \mathrm{H}\right) . ;{ }^{13} \mathrm{C} \mathrm{NMR}\left(63 \mathrm{MHz}, \mathrm{CDCl}_{3}, 25^{\circ} \mathrm{C}\right): \delta=166.8,139.5$, 135.0, 129.0, 125.7, 121.6, 120.7, 112.1, 61.3, 14.4; IR (ATR): $\tilde{v}=3317(\mathrm{~N}-\mathrm{H}), 1688 \mathrm{~cm}^{-1}(\mathrm{C}=\mathrm{O})$. The data match those reported in the literature. ${ }^{[17]}$

\section{6-[(Ethylsulfanyl)methyl]-1H-indazole (10):}

In a dry Schlenk tube under argon were successively added ethyl 1-acetyl- $1 H$-indazole-6-carboxylate 7 (150 mg, $0.65 \mathrm{mmol}, 1.0$ equiv.), triiodoindigane $\mathrm{InI}_{3}(352 \mathrm{mg}, 0.71 \mathrm{mmol}, 1.1$ equiv.) and anhydrous 1,2-dichloroethane $(2 \mathrm{~mL})$. Ethanethiol $(0.2 \mathrm{~mL}, 2.6 \mathrm{mmol}, 4.0$ equiv.) and 1,1,3,3tetramethyldisiloxane (TMDS) $(0.7 \mathrm{~mL}, 3.9 \mathrm{mmol}, 6.0$ equiv. $)$ were then added and the reaction mixture was heated at $60^{\circ} \mathrm{C}$ during $16 \mathrm{~h}$. The completion of the reaction was monitored by TLC and the reaction medium was evaporated to dryness. The crude product was dissolved in $\mathrm{CH}_{2} \mathrm{Cl}_{2}(10 \mathrm{~mL})$, transferred to a separatory funnel and water $(3 \mathrm{~mL})$ was added. The layers were separated and the aqueous phase was then extracted with $\mathrm{CH}_{2} \mathrm{Cl}_{2}(3 \times 5 \mathrm{~mL})$. The combined organic layers were dried over $\mathrm{MgSO}_{4}$, filtered and concentrated. The product was purified by column chromatography (ethyl acetate/cyclohexane 20:80) to yield compound $\mathbf{1 0}(107 \mathrm{mg}, 0.56 \mathrm{mmol}, 86 \%)$ as a white solid. $R_{\mathrm{f}}=0.3$ (ethyl acetate/cyclohexane 30:70); m.p. 66-67 ${ }^{\circ} \mathrm{C} ;{ }^{1} \mathrm{H}$ NMR (300 MHz, $\left.\mathrm{CDCl}_{3}, 25^{\circ} \mathrm{C}\right): \delta=10.09$ (bs, $\left.1 \mathrm{H}\right), 8.05$ $\left(\mathrm{d},{ }^{4} J=0.9 \mathrm{~Hz}, 1 \mathrm{H}\right), 7.71\left(\mathrm{dd},{ }^{3} J=8.3 \mathrm{~Hz},{ }^{4} J=0.9 \mathrm{~Hz}, 1 \mathrm{H}\right), 7.44(\mathrm{~m}, 1 \mathrm{H}), 7.18\left(\mathrm{dd},{ }^{3} J=8.3 \mathrm{~Hz},{ }^{4} \mathrm{~J}=\right.$ $1.4 \mathrm{~Hz}, 1 \mathrm{H}), 3.87(\mathrm{~s}, 2 \mathrm{H}), 2.46\left(\mathrm{q},{ }^{3} J=7.4 \mathrm{~Hz}, 2 \mathrm{H}\right), 1.25\left(\mathrm{t},{ }^{3} J=7.4 \mathrm{~Hz}, 3 \mathrm{H}\right) ;{ }^{13} \mathrm{C} \mathrm{NMR}\left(63 \mathrm{MHz}, \mathrm{CDCl}_{3}\right.$, $\left.25^{\circ} \mathrm{C}\right): \delta=140.4,138.0,134.4,122.7,122.4,120.8,109.6,36.3,25.4,14.3$; IR (ATR): $\tilde{v}=3183 \mathrm{~cm}^{-1}(\mathrm{~N}-$ $\mathrm{H}$ ); HRMS (DCI/CH 4$)$ : calcd for $\mathrm{C}_{10} \mathrm{H}_{13} \mathrm{~N}_{2} \mathrm{~S}[\mathrm{MH}]^{+}: 193.0799$, found: 193.0799. The data match those reported in the literature. ${ }^{[17]}$

\section{Compound 12:}

Conditions A (classical heating): In a dry Schlenk tube under argon, penta-arylbromide 2 (26 $\mathrm{mg}, 17$ $\mu$ mol, 1.0 equiv.), palladium(II) acetate ( $3.9 \mathrm{mg}, 17 \mu$ mol, 1.0 equiv.), $\mathrm{K}_{3} \mathrm{PO}_{4}(72 \mathrm{mg}, 340 \mu \mathrm{mol}, 20$ equiv.), ferroceneboronic acid (156 mg, $680 \mu \mathrm{mol}, 40$ equiv.) and 2-dicyclohexylphosphino-2'-6'dimethoxybiphenyl (SPhos) (14 mg, $34 \mu \mathrm{mol}, 2.0$ equiv.) were successively introduced and degassed anhydrous toluene $(1.5 \mathrm{~mL})$ was added. The resulting suspension was stirred at $100{ }^{\circ} \mathrm{C}$ for 48 hours and the completion of the reaction was monitored by TLC. The reaction mixture was allowed to cool to room temperature, filtered on a neutral alumina pad (using $\mathrm{CH}_{2} \mathrm{Cl}_{2}$ ) and evaporated in vacuo. The residue was purified by column chromatography (neutral alumina, $\mathrm{CH}_{2} \mathrm{Cl}_{2} /$ cyclohexane 30:70) followed (if required) by a recrystallization in a heptane/MeOH mixture (1:1). Complex 12 was obtained as an orange-red solid (6 mg, $2.9 \mu \mathrm{mol}, 17 \%)$.

Conditions B (microwave irradiation): In a dry tube designed for microwave irradiation and under argon, penta-arylbromide $2 \quad$ (50 mg, $33 \mu \mathrm{mol}, \quad 1.0$ equiv.), 1,1'-bis(diphenylphosphino)ferrocenepalladium(II)dichloride dichloromethane $\mathrm{PdCl}_{2}(\mathrm{dppf}) \cdot \mathrm{CH}_{2} \mathrm{Cl}_{2}(27 \mathrm{mg}, 33 \mu$ mol, 1.0 equiv.), sodium tertbutoxide (71 mg, $740 \mu \mathrm{mol}, 22.5$ equiv.), ferroceneboronic acid (57 mg, $246 \mu \mathrm{mol}, 7.5$ equiv.) were successively introduced and degassed anhydrous toluene $(3.6 \mathrm{~mL})$ was added. The tube was sealed and the reaction mixture was heated under microwave irradiation at $135^{\circ} \mathrm{C}$ for $1 \mathrm{~h}$ (a pressure of 5 bar was achieved). The reaction mixture was allowed to cool to room temperature, filtered on a neutral alumina pad (using $\mathrm{CH}_{2} \mathrm{Cl}_{2}$ ) and evaporated in vacuo. The residue was purified by column chromatography (neutral alumina, $\mathrm{CH}_{2} \mathrm{Cl}_{2} /$ cyclohexane 30:70) followed (if required) by a recrystallization in a heptane/MeOH mixture (1:1). Complex 12 was obtained as an orange-red solid (30 mg, $15 \mu \mathrm{mol}, 45 \%$ ). $R_{\mathrm{f}}=0.2\left(\mathrm{CH}_{2} \mathrm{Cl}_{2} /\right.$ cyclohexane 30:70, $\left.\mathrm{SiO}_{2}\right) ;{ }^{1} \mathrm{H} \mathrm{NMR}\left(500 \mathrm{MHz}, \mathrm{CD}_{2} \mathrm{Cl}_{2}, 25^{\circ} \mathrm{C}\right): \delta=8.11\left(\mathrm{br} \mathrm{s}, \sim 3 \mathrm{H}, \mathrm{H}_{\mathrm{a}}\right)$, $7.92\left(\mathrm{bs}, 3 \mathrm{H}, \mathrm{H}_{\mathrm{d}}\right), 7.36\left(\mathrm{~m}, 13 \mathrm{H}, \mathrm{H}_{\mathrm{b}}\right.$ and $\left.\mathrm{H}_{\mathrm{h}}\right), 7.20\left(\mathrm{~d},{ }^{3} \mathrm{~J}=8.5 \mathrm{~Hz}, 10 \mathrm{H}, \mathrm{H}_{\mathrm{i}}\right), 6.99\left(\mathrm{dd},{ }^{3} \mathrm{~J}=8.4 \mathrm{~Hz},{ }^{4} \mathrm{~J}=\right.$ $\left.1.3 \mathrm{~Hz}, 3 \mathrm{H}, \mathrm{H}_{\mathrm{c}}\right), 4.55\left(\mathrm{dd},{ }^{3} J=1.9 \mathrm{~Hz},{ }^{4} J=1.8 \mathrm{~Hz}, 10 \mathrm{H}, \mathrm{H}_{\mathrm{j}}\right), 4.24\left(\mathrm{dd},{ }^{3} J=1.9 \mathrm{~Hz},{ }^{4} J=1.8 \mathrm{~Hz}, 10 \mathrm{H}\right.$, $\mathrm{H}_{\mathrm{k}}$ ), $3.94\left(\mathrm{~s}, 25 \mathrm{H}, \mathrm{H}_{\mathrm{l}}\right), 3.90\left(\mathrm{~s}, 6 \mathrm{H}, \mathrm{H}_{\mathrm{e}}\right), 2.48\left(\mathrm{q},{ }^{3} \mathrm{~J}=7.3 \mathrm{~Hz}, 6 \mathrm{H}, \mathrm{H}_{\mathrm{f}}\right), 1.28\left(\mathrm{t},{ }^{3} J=7.3 \mathrm{~Hz}, 9 \mathrm{H}, \mathrm{H}_{\mathrm{g}}\right.$ ); 
${ }^{13} \mathrm{C}$ NMR $\left(125 \mathrm{MHz}, \mathrm{CD}_{2} \mathrm{Cl}_{2}, 25^{\circ} \mathrm{C}\right): \delta=144.1\left(\mathrm{C}_{2}\right), 140.4\left(\mathrm{C}_{1}\right), 138.6\left(\mathrm{C}_{15}\right), 137.6\left(\mathrm{C}_{5}\right), 133.9\left(\mathrm{C}_{13}\right)$, 132.4 $\left(\mathrm{C}_{12}\right), 125.1\left(\mathrm{C}_{14}\right), 122.6\left(\mathrm{C}_{7}\right), 122.4\left(\mathrm{C}_{4}\right), 120.4\left(\mathrm{C}_{3}\right), 111.4\left(\mathrm{C}_{6}\right), 87.8\left(\mathrm{C}_{11}\right), 84.7\left(\mathrm{C}_{16}\right), 70.2\left(\mathrm{C}_{19}\right)$, $69.6\left(\mathrm{C}_{17}\right), 66.7\left(\mathrm{C}_{18}\right), 36.9\left(\mathrm{C}_{8}\right), 25.7\left(\mathrm{C}_{9}\right), 14.8\left(\mathrm{C}_{10}\right)$; UV/Vis $\left(\mathrm{CH}_{2} \mathrm{Cl}_{2}\right): \lambda_{\max }(\varepsilon)=292(30300), 340 \mathrm{~nm}$ (16000 $\mathrm{mol}^{-1} \mathrm{dm}^{3} \mathrm{~cm}^{-1}$ ); HRMS (ESI+): calcd for $\mathrm{C}_{115} \mathrm{H}_{99} \mathrm{BFe}_{5} \mathrm{~N}_{6} \mathrm{RuS}_{3}[\mathrm{MH}]^{+}: 2053.3108$, found: 2053.3103.

\section{Acknowledgements}

This work was supported by the University Paul Sabatier (Toulouse, France), the Centre National de la Recherche Scientifique (CNRS), the Agence Nationale de la Recherche (ANR) (ACTION project ANR15-CE29-0005) and the European Union by the H2020 FET-OPEN project MEMO (Mechanics with Molecules, Grant N`766864).

\section{References and Notes}

[1] a) V. Balzani, A. Credi, M. Venturi, Molecular Devices and Machines: Concepts and Perspectives for the Nanoworld, Wiley-VCH, Weinheim, 2nd edn, 2008; b) J.-P. Sauvage, Angew. Chem. 2017, 129, 11228-11242; Angew. Chem. Int. Ed. 2017, 56, 11080-11093; c) C. J. Bruns, J. F. Stoddart, The Nature of the Mechanical Bond: From Molecules to Machines, John Wiley and Sons, Hoboken, 2016.

[2] a) S. Erbas-Cakmak, D. A. Leigh, C. T. McTernan, A. L. Nussbaumer, Chem. Rev. 2015, 115, 10081-10206; b) C. Pezzato, C. Cheng, J. F. Stoddart and R. D. Astumian, Chem. Soc. Rev. 2017, 46, 5491-5507.

[3] a) J. C. Chambron, C. Dietrich-Buchecker, G. Rapenne, J.-P. Sauvage, Chirality 1998, 10, 125-133; b) G. S. Kottas, L. I. Clarke, D. Horinek, J. Michl, Chem. Rev. 2005, 105, 1281-1376; c) E. R. Kay, D. A. Leigh, F. Zerbetto, Angew. Chem. 2007, 119, 72-196; Angew. Chem. Int. Ed. 2007, 46, 72-191; d) S. Kassem, T. van Leeuwen, A. S. Lubbe, M. R. Wilson, B. L. Feringa, D. A Leigh, Chem. Soc. Rev. 2017, 46, 2592-2621 and references therein.

[4] T. R. Kelly, H. De Silva, R. A. Silva, Nature 1999, 401, 150-152.

[5] N. Koumura, R. W. J. Zijlstra, R. A. van Delden, N. Harada, B. L. Feringa, Nature 1999, 401, 152-155.

[6] a) R. Eelkema, M. M. Pollard, J. Vicario, N. Katsonis, B. S. Ramon, C. W. M. Bastiaansen, D. J. Broer, B. L. Feringa, Nature 2006, 440, 163; b) K.-Y. Chen, O. Ivashenko, G. T. Carroll, J. Robertus, J. C. M. Kistemaker, G. London, W. R. Browne, P. Rudolf, B. L. Feringa, J. Am. Chem. Soc. 2014, 136, 3219-3224; c) Q. Li, G. Fuks, E. Moulin, M. Maaloum, M. Rawiso, I. Kulic, J. T. Foy, N. Giuseppone, Nat. Nanotechnol. 2015, 10, 161-165; d) A. Saywell, A. Bakker, J. Mielke, T. Kumagai, M. Wolf, V. Garcia-Lopez, P.-T. Chiang, J. M. Tour, L. Grill, ACS Nano 2016, 10, 10945-10952.

[7] H. L. Tierney, C. J. Murphy, A. D. Jewell, A. E. Baber, E. V. Iski, H. Y. Khodaverdian, A. F. McGuire, N. Klebanov, E. C. H. Sykes, Nat. Nanotechnol. 2011, 6, 625-629.

[8] T. Kudernac, N. Ruangsupapichat, M. Parschau, B. Macia, N. Katsonis, S. R. Harutyunyan, K.-H. Ernst, B. L. Feringa, Nature 2011, 479, 208-211.

[9] U. G. E. Perera, F. Ample, H. Kersell, Y. Zhang, G. Vives, J. Echeverria, M. Grisolia, G. Rapenne, C. Joachim, S.-W. Hla, Nature Nanotechnol. 2013, 8, 46-51.

[10] Y. Zhang, H. Kersell, R. Stefak, J. Echeverria, V. Iancu, U. G. E. Perera, Y. Li, A. Deshpande, K.-F. Braun, C. Joachim, G. Rapenne, S.-W. Hla, Nature Nanotech. 2016, 11, 706-712.

[11] G. Vives, G. Rapenne, Tetrahedron 2008, 64, 11462-11468.

[12] a) C. Joachim, G. Rapenne, Top. Curr. Chem. 2014, 354, 253-277; b) R. Stefak, A. M. Sirven, S. Fukumoto, H. Nakagawa, G. Rapenne, Coord. Chem. Rev. 2015, 287, 79-88; c) C. Kammerer, G. Rapenne, Eur. J. Inorg. Chem. 2016, 2214-2226.

[13] a) G. Vives, G. Rapenne, Tetrahedron Lett. 2006, 47, 8741-8744; b) G. Vives, A. Carella, S. Sistach, J.-P. Launay, G. Rapenne, New. J. Chem. 2006, 30, 1429-1438; c) G. Vives, A. Gonzalez, J. Jaud, J.-P. Launay, G. Rapenne, Chem. Eur. J. 2007, 13, 5622-5631.

[14] A. Carella, R. Poteau, G. Rapenne, J.-P. Launay, Chem. Eur. J. 2008, 14, 8147-8156. 
[15] N. G. Connelly, I. Manners, J. Chem. Soc., Dalton Trans., 1989, 30, 283-288.

[16] Unpublished results.

[17] A. Carella, G. Vives, T. Cox, J. Jaud, G. Rapenne, J.-P. Launay, Eur. J. Inorg. Chem. 2006, 980-987.

[18] T. Miyazaki, S. Kasai, Y. Ogiwara, N. Sakai, Eur. J. Org. Chem. 2016, 1043-1049.

[19] For a recent review on the use of TMDS in organic synthesis, see: J. Pesti, G. L.Larson, Org. Process Res. Dev. 2016, 20, 1164-1181.

[20] N. Sakai, K. Fujii, T. Konakahara, Tetrahedron Lett. 2008, 49, 6873-6875.

[21] S. Trofimenko, Chem. Rev. 1993, 93, 943-980.

[22] C. Santini, M. Pellei, G. Gioia Lobbia, G. Papini, Mini-Rev. Org. Chem. 2010, 7, 84-124.

[23] M. Kitamura, Y. Takenaka, T. Okuno, R. Holl, B. Wünsch, Eur. J. Inorg. Chem. 2008, 1188-1192.

[24] K. Tsuda, K. Miyata, T. Okuno, M. Yoshimura, S. Tanaka, M. Kitamura, Tetrahedron Lett. 2008, $2990-2993$.

[25] T. W. Greene, P. G. M. Wuts, Protective Groups in Organic Synthesis, Third Edition, John Wiley and Sons, New York, 1999, pp. 552-554.

[26] H.-P. Jacquot de Rouville, D. Villenave, G. Rapenne, Tetrahedron 2010, 66, 1885-1891. 